\title{
SAN HIPÓLITO, UN ESPACIO DE DEVOCIÓN Y ENUNCIACIÓN POLÍTICA PARA LOS SANJUDEROS EN LA CIUDAD DE MÉXICO
}

\author{
ST. HIPÓLITO, A SPACE OF DEVOTION AND POLITICAL \\ ENUNCIATION FOR THE SANJUDEROS IN THE CITY OF MEXICO
}

\author{
Thania Sttephanni Álvarez Juárez*
}

RESUMEN

El templo de San Hipólito en la Ciudad de México es un espacio sagrado que ha sido estigmatizado como un lugar de encuentro de jóvenes adictos y delincuentes devotos a San Judas Tadeo (sanjuderos), que acuden cada 28 de mes, día en que celebran al santo en la ciudad. Para romper el estigma, este artículo tiene como objetivo mostrar los distintos perfiles de los devotos y sus formas de apropiación espacial. Mediante una perspectiva geográfica y un acercamiento etnográfico, con una asistencia metódica cada 28 de mes, el presente trabajo encuentra que a este templo acuden desde niños hasta mujeres $y$ hombres de la tercera edad; amas de casa, obreros, comerciantes informales, sindicalizados, estudiantes de clases populares y colonos; así como, migrantes (indígenas y mestizos); todos marginados y característicos de las grandes urbes latinoamericanas. De esta forma, a través del culto popular urbano a San Judas Tadeo en el templo de San Hipólito, los sectores marginados de la ciudad y su periferia pueden visibilizarse, se apropian de este espacio cada mes, lo hacen un espacio devocional, al tiempo que festivo y de enunciación política. Es parte de una tercera apropiación en la historia del templo, en una lógica de resemantización.

PALABRAS CLAVE: MÉXICO * ESPACIO * ETNOGRAFÍA * URBANO * CULTO

\section{ABSTRACT}

The temple of San Hipolito, in Mexico City, is a sacred space that has been stigmatized as a meeting place for young addicts and delinquents devoted to San Judas Tadeo (sanjuderos), who come every 28th of the month, the day they celebrate to the saint in the City. To break the stigma, this article aims to show the different profiles of the devotees and their forms of spatial appropriation. Through a geographical perspective and an ethnographic approach, with a methodical assistance every 28th of the month, the present work finds

Estudiante de posgrado en el Instituto de Geografía, Universidad Nacional Autónoma de México, México. thangea@live.com 
that, to this temple go from children to women and men of the third age; housewives, workers, informal merchants, union members, students of popular classes and settlers; as well as migrants (indigenous and mestizo). In this way, through the urban popular cult to San Judas Tadeo in the temple of San Hipolito, the marginalized sectors of the city and its periphery can become visible, they take over this space every 28th of the month, they make it a devotional space, while of festive funtion and political enunciation. It is part of a third appropriation in the history of the temple, in a logic of resemantization.

KEYWORDS: MEXICO * SPACE * ETHNOLOGY * URBAN * CULTO

Mediáticamente, desde los primeros años del 2000, la devoción a San Judas Tadeo en torno al templo de San Hipólito y San Casiano, colonia Guerrero, en el Centro Histórico, alcaldía de Cuauhtémoc en la Ciudad de México, se ha relacionado exclusiva y erróneamente con judiciales (policías) y con jóvenes de barrios o colonias populares, en su mayoría dedicados a actividades ilícitas o simplemente, "ni estudian ni trabajan". Todos estos jóvenes son señalados discriminatoriamente como "nacos"1 "ñeros" y, de forma más reciente, como "chacas", este calificativo se asocia a un nivel económico, social y cultural bajo; color de piel moreno y pelo pintado de rubio; al consumo de "activo"2, gusto por el reggaetón, delincuencia y a una forma de vestir ${ }^{3}$. Para este artículo, si bien estos jóvenes vulnerables y sujetos dedicados a actividades ilícitas forman parte de la población devota en el templo, no es de manera exclusiva, al templo asisten diversos perfiles de devotos; sin embargo,

1 Es un mexicanismo, quizá de totonaco; adjetivo despectivo referente a indio. Forma despectiva de llamar a lo procedente de los sectores urbanos populares (Real Academia de la Lengua Española).

Drogas inhalables más comunes y de bajo costo en México, por ejemplo, el thinner en estopa, "mona". existe una importante producción académica ${ }^{4}$ enfocada en la imagen mediática.

De tal suerte, en México, se ha creado un estigma espacial y social en torno al templo $y$ a los devotos, $y$ se han ignorado los procesos históricos y espaciales que le dieron origen; particularmente, se ha invisibilizado la presencia de una población devota configurada por generaciones de migrantes mestizos e indígenas, propias de las grandes urbes latinoamericanas. Los devotos a San Judas Tadeo (sanjuderos), en su mayoría, pertenecientes a los sectores marginados de la Ciudad de México y su periferia, mediante una religiosidad popular urbana, buscan una alternativa ante la incertidumbre económica e institucional del país y del contexto urbano. Así, cada 28 de mes, especialmente el 28 de octubre (fiesta anual), los sanjuderos se apropian del templo de San Hipólito y sus espacios circundantes: las estaciones del transporte metropolitano Hidalgo, Bellas Artes y Guerrero; Paseo de la Reforma; avenida Hidalgo; plaza Zarco y el jardín San Fernando, para implorarle a "San Juditas" o al "Patrón", como lo llaman, al tiempo que resisten, se visibilizan y festejan.

\section{LA RELIGIOSIDAD POPULAR COMO ALTERNATIVA EN LAS GRANDES URBES LATINOAMERICANAS}

Para Masferrer (2013), los científicos sociales latinoamericanos recurren a conceptos provenientes de ámbitos culturales dominantes, como inercia a las modas conceptuales de los centros

$4 \quad$ Ver ejemplos: Luna (2016), Mancillas (2012) y Mejía (2012). debajo de la cadera, gorras, lentes de sol, tenis y playeras con una decoración sumamente llamativa, la mayoría imitación de marcas muy reconocidas (ultra-lujo); así como, collares, aretes, cadenas, pulseras y escapularios, regularmente con la imagen de San Judas Tadeo o la Santa Muerte. 
hegemónicos, y no construyen conceptos adecuados a la multietnicidad y pluriculturalidad latinoamericana. Enfatiza en el término "religiosidad popular" o "catolicismo popular", definido a grandes rasgos como: "forma en que se expresan religiosamente, para dar un sentido trascendente a su vida, las grandes mayorías del pueblo de América Latina, que se definen a sí mismas como católicas, a pesar de su escaso cultivo religioso [...]" (Marzal, 2002, pp. 315316). Desde su perspectiva, este término ignora dicha complejidad histórica y cultural heredada por las cosmovisiones indígenas; por ejemplo, como sucede en México con los elementos de la cosmovisión mesoamericana. A su vez, de ser aceptado el término por el científico social, aceptaría que este se circunscribe al pueblo $y$ que las clases altas no crean sus propias propuestas religiosas (Masferrer, 2013).

No obstante, vale la pena retomar la observación de José Luis González (1996), para quien las experiencias cristianas de la élite son muy diferentes a las experiencias del pueblo, aunque existan lazos simbólicos que comparten una imprecisa realidad, el catolicismo. En Latinoamérica, las experiencias de la élite son distintas a las del pueblo, con énfasis en el espacio urbano. Si bien, existen elementos comunes entre una religiosidad practicada por clases altas y medias - como las prácticas devocionales y promesas a los santos y/o la Virgen-que las vinculan a grupos trabajadores, subproletariados, campesinos y masas de desempleados $y$ subempleados, estas prácticas en estos últimos se dan dentro de una cultura popular, $y$ tienden a disminuir su expresión entre más alta sea la escala social (Parker, 1993).

La religiosidad popular debe ser vista como resistencia del pueblo oprimido ante las clases dominantes, y no como una expresión religiosa exótica; es un conjunto de ritos, creencias $y$ un saber oral recreados en la memoria del pueblo. Es el pueblo que crea y recrea el campo religioso (Rosendahl, 1996). Este artículo reconoce las acertadas e indiscutibles aportaciones de Masferrer (2013), pero considera que la devoción a San Judas Tadeo en el templo de San Hipólito, representa una clara manifestación de una religiosidad popular, específicamente de una religiosidad popular urbana. Desde este punto de vista, no se refiere a la religiosidad popular desde una mirada peyorativa o institucional, sino como una creación del pueblo latinoamericano, a través de la cual, se visibiliza en el espacio apropiándose de este; es el empoderamiento del pueblo mediante prácticas rituales propias y su territorialización.

Existe una aportación dada por Cristian Parker (1993) más adecuada para este estudio, "religiosidad popular urbana", que puntualiza sobre las características de la religiosidad popular en el espacio urbano latinoamericano y la heterogeneidad social de las ciudades de la región; dado que el área de estudio, la Ciudad de México, es un espacio urbano que reune esa diversidad espiritual, cultural, fusión étnica y religiosa de este país (Gutiérrez, 2005). En este artículo se utilizará el término:

La religión popular urbana es un término genérico del que no se debe abusar, dado que recubre una multiplicidad muy heterogénea de expresiones religiosas que corresponden a las mayorías populares que habitan en las periferias y suburbios de las grandes y medianas ciudades latinoamericanas. Su sujeto es el complejo y diversificado mundo de las clases urbano-populares, obreros industriales, trabajadores por cuenta propia, desocupados, mujeres pobladoras, jóvenes estudiantes de ambientes populares, marginados de todo tipo, clases y capas vinculadas complejamente con los procesos de modernización capitalista y su modalidad en América Latina (Parker,1993, p.166).

Estas expresiones religiosas, desarrolladas hace más 70 años al interior de la cultura popular urbana de América Latina, se expresan en aquellos espacios urbanos, colonias proletarias, barriadas marginales, villas miseria o favelas, resultado de las abominables desigualdades de la región (Parker, 1993). Estos espacios son concentradores de generaciones 
de campesinos que, al asentarse en el hábitat urbano, se incorporan social y simbólicamente al modo de vida $y$ valores de este, por lo tanto, su religión se ve afectada; por ejemplo, para su sobrevivencia en vez de los ciclos naturales y su estrecha vinculación con la tierra, incorpora sus propias estrategias de subsistencia o depende de la obtención de un trabajo. Se transforma en una religiosidad periódica influenciada por momentos críticos de la vida como el divorcio, una tragedia, muerte, desempleo o enfermedad; además de ser menos folclórica, festiva y multitudinaria, pues encuentra su masividad en el mitin político (Parker, 1993).

Cabe hacer un paréntesis respecto a las características menos festivas o multitudinarias, pues la peregrinación, como expresión por excelencia de la religiosidad popular, en el ámbito urbano no forzosamente pierde su masividad $y$ no se sustituye en el mitin político. Si bien, los sectores maginados no están plenamente conscientes de su postura crítica mediante su práctica religiosa, sus expresiones a través de sus códigos simbólicos les permiten manifestarse sin temor a la represión. Debe hacerse hincapié, que la conciencia social dialéctica en el caso de los sectores urbano-marginales o sectores subalternos es menos evidente que en el ámbito rural, debido al proceso de occidentalización experimentado; aun así, la religiosidad popular no deja de ser un proyecto alternativo (González, 1996).

Las peregrinaciones a San Judas Tadeo hacia el templo de San Hipólito y San Casiano, evidentes en las calles de la Ciudad de México cada 28 de mes y con énfasis el 28 de octubre, están caracterizadas por su masividad y fuerte carga política. Son rituales a través de los cuales, sindicatos, colonos, familias, amigos, oficinistas, estudiantes, indígenas migrantes y de pueblos originarios $^{5}$, hasta sujetos al margen de la ley, provenientes de alcaldías y de la periferia de la

$5 \quad$ Pueblos que, anterior a la colonización, se encontraban muy organizados y estructurados, además, conectados en toda la región mesoamericana. Conservan algunos de sus elementos culturales: lengua; organización social en redes de parentesco ritual, fiestas y santos; organización territorial en pueblos y barrios (Oehmichen, 2015).
Ciudad de México, se visibilizan en la ciudad y territorializan su fe, al tiempo que demandan la intercesión de San Judas Tadeo. Es la lucha por un trabajo, por atención médica, salud, dinero, salir de prisión, dejar las drogas, entre muchas otras "causas difíciles".

\section{EL ESPACIO SAGRADO COMO ESPACIO DE ENUNCIACIÓN POLIITICA Y FESTIVIDAD: SAN HIPÓLITO}

Desde un punto de vista geográfico, la religión puede analizarse mediante la apropiación de determinados segmentos del espacio. Los espacios apropiados son denominados territorios, así, la territorialidad es el control del territorio por un conjunto de prácticas de instituciones o grupos; la religión, por lo tanto, crea sus propios territorios (Rosendahl, 1996).

Para Cristina Teresa Carballo (2009), en su trabajo intitulado, Repensar el territorio de la expresión religiosa, el territorio requiere del espacio: "[...] el territorio un espacio apropiado, ocupado y dominado por un grupo social para asegurar su reproducción y satisfacer las necesidades vitales, que pueden ser tanto materiales como simbólicas" (p. 28). De esta manera, el trabajo de Carballo tiene algunas de sus bases teóricas en el geógrafo Claude Raffestin, quien encuentra que los tres elementos del territorio son: apropiación del espacio, poder y frontera. Cuando hay una apropiación hay una necesidad de frontera, un componente básico en la construcción de la identidad y la alteridad que se sustenta justamente en el territorio. La frontera del territorio se manifiesta como "[...] conjunto de representaciones colectivas derivadas de sistemas de relaciones al interior de un grupo, las que se encuentran mediadas por la memoria y cultura compartida. [...] La frontera se define entonces como diferenciador cultural, territorial y temporal" (Carballo, 2009, p.37).

En América Latina, las peregrinaciones son expresiones del pueblo que mediante procesos rituales accionan valores y símbolos dominantes de la sociedad; son rituales de tránsito liminal que llevan a las personas de un estado a otro, es el paso del espacio-tiempo profano al espacio-tiempo sagrado (rituales de paso). Los creyentes se apropian del espacio 
sagrado (santuario), se territorializa a lo largo de la ruta peregrina, los creyentes materializan en el espacio su reproducción simbólica (Carballo, 2009).

Rosendahl (1996 y 1999), en su teoría del espacio sagrado, identifica en un templo o santuario tres funciones: devocional, política y turística, definidas por las formas de apropiarse del espacio. Las características políticas, socioeconómicos y culturales de los devotos a San Judas Tadeo, estas últimas permeadas por elementos indígenas (mesoamericanos) y coloniales, se manifiestan en sus formas de apropiación espacial del templo de San Hipólito; de tal forma, este espacio representa un espacio de función devocional y también de enunciación política para los sectores marginados, a los que pertenecen la mayoría de los sanjuderos, esto, sin afán de excluir a otras clases sociales presentes en el templo, aunque en menor número, con tiempos y modos de apropiación distintos (patrones espacio-temporales) (cuadro 1).

Las peregrinaciones a San Judas Tadeo de cada 28 de mes, consolidan su objetivo y se apropian a su vez del templo de San Hipólito y San Casiano, lo hacen suyo a su manera (desinstitucionalización), desde su posición social, económica, política y cultural. Le imprimen más que una función devocional, constituye un espacio de enunciación política y festividad para los grupos subalternos con una memoria y cultura compartida. Si bien, la función turística está presente, es muy incipiente y su influencia es mínima, más bien configurada por la cercanía con los espacios turísticos del Centro Histórico de la Ciudad de México; es una dinámica turística que transita entre el turismo religioso y el cultural. De tal suerte, el presente artículo no considera la función turística como elemento de trascendencia.

FUNCIONES DEL ESPACIO SAGRADO Y SUS FORMAS DE APROPIACIÓN

FUNCIONES

APROPIACIÓN

La organización y distribución de los símbolos en el espacio que identifican a un grupo social, a modo de un "paisaje" que ofrece una identidad espacial. La organización del santuario debe

\section{$\begin{array}{ll}\text { Función devocional } & \text { a modo de un "paisaje" que ofrece una identidac } \\ & \text { aproximar al devoto a Dios (Rosendahl, 1999). }\end{array}$}

El espacio sagrado visto también como espacio político, donde sectores oprimidos o Función política marginados de la sociedad, por ejemplo, migrantes, se identifican como un grupo digno y con identidad propia; puede representar un símbolo nacional o una materialización (territorio) del poder de la comunidad (Rosendahl, 1999).

Función festiva

Dado que, una de las características de la religiosidad popular es su fuerte ánimo festivo, este también produce al espacio sagrado como al espacio circundante. Esta función representa un espacio-tiempo alejado del cotidiano de la urbe, la oportunidad de convivir y festejar.

Fuente: Elaboración propia.

Los 28 de cada mes, en la Ciudad de México, en una forma de "organización popular urbana no institucional", se puede ver en el transporte público (autobuses, Metrobús y Metropolitano) y en sus calles, andar peregrinos con su "San Juditas" en brazos, en andas, sobre la espalda, tatuado en su cuerpo o contenido en los colores de un collar, hasta llegar al altar del templo de San Hipólito. Es una apropiación del espacio o territorialización diferenciada del resto de los días, cuando comparten este espacio con devotos de otros grupos sociales. Así, 
soterrando su advocación oficial (San Hipólito) es, sin lugar a dudas, "la casa de San Judas Tadeo", cuya imagen actualmente ocupa la mayor jerarquía del templo, el altar. En el templo de San Hipólito, la llegada masiva de devotos pone en constante tensión la relación dicotómica institucionalización-desinstitucionalización, pues la fuerte atracción de este templo refrenda la necesidad de un espacio dedicado específicamente al culto, pero también, de un espacio de enunciación y visibilización para los subalternos. De manera festiva, en tanto que disruptiva para la institución católica y sin importar la homilía, los sanjuderos manifiestan sus necesidades, carencias, tristezas, ilusiones, alegrías, deseos, miedos, esperanzas y desesperanzas; salen a las calles $y$ toman el templo, sin importar señalamientos $y$ estigmas, ellos encuentran un espacio para ellos y de ellos.

En su función festiva, los espacios abiertos circundantes al templo de San Hipólito, plaza Zarco, avenida Hidalgo y Paseo de la Reforma, cada 28 de mes son también apropiados por numerosos puestos ambulantes configuradores de una economía informal creciente, orientada a los peregrinos y no al turismo; venta de comida a bajo costo, veladoras, playeras con la imagen de San Judas Tadeo, e imágenes de bulto de diversas manifestaciones de lo sagrado (Virgen de Guadalupe, Cristo, Santa Muerte, Malverde, Buda, Hadas y San Judas Tadeo, entre otros) dibujan un "paisaje devocional" a modo de una síntesis de la diversidad religiosa y cultural actual de la urbe. Cerca de 20000 devotos el 28 de mes y más de 80000 el 28 de octubre, se dan cita en este lugar a manera de una gran fiesta, para muchos de ellos, al término de su peregrinar, representa un día familiar, una oportunidad entre amigos para escabullirse del cotidiano; comer, beber, obtener regalos y otras dádivas ofrecidas por devotos, como agradecimiento por algún favor recibido del santo. Para muchos en situación de calle, que habitan en las calles aledañas del templo, representa la oportunidad de llevar a la boca un plato de comida.

Estas manifestaciones actuales de la devoción por San Judas Tadeo, en el templo de
San Hipólito, no podrían entenderse sin hablar de los procesos históricos que tuvieron distintas formas de apropiación de este espacio sagrado y sus espacios circundantes, hasta llegar a su apropiación actual. De tal forma, este santo no siempre estuvo vinculado a sectores marginados ni delincuenciales de la Ciudad de México, más bien, es resultado de cambios económicos, sociales, políticos $y$, evidentemente, culturales, como la migración, el empobrecimiento de la población y la violencia desmedida, reflejados en la resemantización de la devoción y la incorporación a su capital simbólico de nuevos elementos, antes ajenos a esta, como la Santa Muerte o Jesús Malverde. Por su historia, la devoción debe entenderse en tres periodos de apropiación espacial: 1955-1970, 1982-1990 y 2002-2018.

\section{PROCESOS HISTÓRICOS Y APROPIACIONES ESPACIALES DEL TEMPLO DE SAN HIPÓLITO}

De acuerdo con la tesis de Irving Santiago Patraca $(\mathrm{CMF})^{6}$ (2013), La devoción a San Judas Tadeo, espacio teológico para expresar la fe de un pueblo y Lugar de encuentro con el resucitado, para entender la devoción de San Judas Tadeo ${ }^{7}$ en la Ciudad de México, debe partirse del año de 1932, en el templo de Jesús María, la segunda casa de los Misioneros Claretianos desde 1887, pues la primera se encontraba en Toluca, Estado de México, desde 1884.

Hacia el año 1932, pasadas las mayores tensiones de la Guerra Cristera (Cristiada), el culto en los templos de Jesús María, en la Ciudad de México y en el Bajío, regresó a la normalidad. Los Misioneros Claretianos (2014) mencionan ese año cuando se realizó en el

$6 \quad$ En latín: Cordis Marice Filius (Hijos del Inmaculado Corazón de María).

7 Para los Misioneros Claretianos (2014), San Judas Tadeo nació probablemente en Galilea, fue primo hermano de Jesús; sus hermanos fueron Santiago, Simón y José. Formó parte de los 12 apóstoles. El nombre "Judas" en hebreo significa "alabanzas sean dadas a Dios", mientras "Tadeo", en arameo, significa "valiente o magnánimo". No es Judas Iscariote. Fue martirizado y murió en el año 62, en Persia. La iglesia dedica el 28 de octubre al martirio de San Judas Tadeo y San Simón. 
templo de Jesús María, por primera vez, una novena a San Judas Tadeo, aunque no contaban con la imagen; cabe decir que, la feligresía de este templo eran personas con buenos recursos económicos; pero, ante el temor que todavía permeaba a los creyentes, la devoción por el santo decayó. A fin de promover nuevamente la devoción, el sacerdote Julián Collel (CMF) logró obtener una imagen del santo proveniente de España, y el 30 de mayo de 1933 llegó la imagen al templo de Jesús María (Santiago, 2013).

Pese a los esfuerzos, en 1934, tras una orden oficial para convertir el templo de Jesús María en el Archivo Histórico Militar, el templo cerró sus puertas al culto, y la imagen de San Judas Tadeo se trasladó a la parroquia del Purísimo Corazón de María, en la colonia Del Valle, también en la Ciudad de México. Para el año de 1936, la imagen fue trasladada al estado de Puebla, a fin de difundir la devoción al santo (Santiago, 2013). Finalmente, regresa a la Ciudad de México en 1955, al templo de San Hipólito y San Casiano, la tercera casa de los Claretianos desde 1892, donde las labores pastorales o de ayuda y acompañamiento se realizaban en grupos sociales distintos al templo de Jesús María; en San Hipólito se brindaba atención humana, espiritual e institucional a los sordos de su escuela anexa, Rosendo Olleta; y a limpia botas, vendedores de periódicos, obreros y empleados de la Asociación Guadalupana de Obreros (Santiago, 2013).

Por lo explicitado, el origen de la devoción en México parte de la primera novena a San Judas Tadeo que tuvo lugar en el templo de Jesús María en la Ciudad de México, en el año de 1932; esto, contradice la propuesta del grupo de investigación social Habitus ${ }^{8}$ (2011a) que, en su artículo San Judas Tadeo en la Ciudad de México. Los orígenes de la devoción, arguye que la devoción a San Judas Tadeo llegó

$8 \quad$ Ávila Romero, José Luis; Robles Cárdenas, Grizel; Maldonado Macedo, Vanessa y Serna Luna Erick. "Una juventud religiosa. Jóvenes vulnerables y San Judas Tadeo". Proyecto ganador del concurso Creación Joven 2009, auspiciado por el Instituto de Ciencia y Tecnología del Distrito Federal (ICTyDF); Secretaria de Desarrollo Social (SEDESOL) y el Instituto Mexicano de la Juventud (IMJUVE). en el año de 1955, proveniente de la ciudad de Chicago, Estados Unidos, donde la devoción se encontraba anclada gracias a la labor del sacerdote James Tort, desde 1929. En este punto, cabe hacer un paréntesis en el clásico de referencia para los estudios de San Judas Tadeo, Thank You, St. Jude: Women's Devotion to the Patron Saint of Hopeless Causes, de Robert A. Orsi (1996).

El sacerdote James Tort fue miembro de los Claretianos y llegó a la ciudad de Chicago en 1925. Para el verano de 1927, el padre Tort fundó la Sociedad de ayuda mexicana, con la finalidad de brindar apoyo espiritual a la comunidad migrante de mexicanos que se encontraba al Sur de esa ciudad (Orsi,1996). Ahí, en 1928, se colocó la primera piedra de la parroquia de Nuestra Señora de Guadalupe, ante la presencia de cerca de 10000 personas (polacos, irlandeses, alemanes y croatas, entre otros) (Orsi,1996).

Tort, que tenía una importante feligresía, en el contexto de la crisis económica de 1929 (La gran depresión de 1929), llevó a cabo una novena (17 de febrero) para San Judas Tadeo, cuyo acercamiento obedeció a una imagen que le fue regalada en una misión a Arizona en 1923 , por un minero chileno, pues la devoción tenía presencia como un pequeño culto en América Central y del Sur, y se relacionaba con sectores marginados de esa ciudad (Orsi,1996). Así, para el 28 de octubre de 1929, más de 1000 personas se reunieron en la inconclusa parroquia de Nuestra Señora de Guadalupe para rezar la novena y festejar. Entonces, floreció el culto a San Judas Tadeo en Estados Unidos, relacionado con los migrantes y mujeres en situaciones difíciles, salud y causas desesperadas (Orsi, 1996 y Santiago, 2013).

Con este contexto, para los primeros años de la década de los 30 del siglo xx, comenzaba a configurarse una devoción por San Judas Tadeo de alcance nacional en Estados Unidos, ligada principalmente a sectores marginados, como los grupos de migrantes; mientras en la Ciudad de México, para el año de 1932, la devoción ya estaba presente en el templo de Jesús María, pero difundida, principalmente, entre personas de nivel socioeconómico medio 
$y$ alto, feligreses de este templo $y$ de manera muy local, sin pasar de los límites de la ciudad. Este artículo encuentra probable que, en esta década, el culto haya llegado a México por el intercambio entre la comunidad claretiana de ambos países. En el caso de México, después de la represión vivida durante la Cristiada, la institución católica requería una estrategia y un símbolo unificador de masas, como San Judas Tadeo, cuya eficacia fue comprobada en el país del norte. De tal suerte, en un inicio la devoción por San Judas Tadeo no fue masiva ni se ancló con fuerza, pero hacia 1955 encontraría una necesidad común entre las masas.

En este sentido, la devoción no llegó en el año 1955, más bien, en 1955 se ancló en una población devota del santo distinta a la existente desde 1932; el estrato social y cantidad de población en la cual tuvo su difusión sería notablemente distinta a su llegada inicial en el templo de Jesús María. Fue el sacerdote Antonio Bandrés (CMF) el primero en promover la devoción en el templo de San Hipólito, a la llegada de la imagen en 1955 a este templo; de hecho, mucho tuvo que ver el traslado de la imagen de San Judas Tadeo a la capilla de los Mártires mexicanos, en 1958. Así, la devoción al santo llegó a apropiarse, en un primer proceso, del templo de San Hipólito, pero con características poblacionales del país vecino, predominantemente entre obreros, trabajadores informales, amas de casa y también entre migrantes y policías. Esta circunstancia puede ser un atisbo para entender el proceso de resemantización que ha tenido la devoción en México, sin soslayar las condiciones sociales, económicas, políticas y culturales de este país, así como, las características locales de la Ciudad de México.

Para apoyar esta hipótesis, Macías (2016) encuentra en el año de 1955, el momento que el culto a San Judas Tadeo comenzó a tener un lugar destacado dentro de la feligresía católica de la Ciudad de México, ya que la devoción presente en 1932 solo fue un primer momento de referencia sin mayor importancia. Este autor, al igual que el presente artículo, apoya el argumento de Habitus (2011a), en el sentido que, fueron los movimientos migratorios de retorno
(Estados Unidos a México) el vínculo de contacto de la devoción de ambos países y, también, el medio de difusión entre familiares y amigos, lo que configuró una mayor feligresía.

Al respecto, el R.P. ${ }^{9}$ Ramón Rivera Barriga (CMF), quien llegó al templo de San Hipólito en 1970 y actualmente, es el Superior del templo, señala ${ }^{10}$ el papel de la capilla de los Mártires mexicanos, en el templo de San Hipólito, como el primer espacio de culto a San Judas Tadeo en esta primera etapa de apropiación, pues desde entonces $y$ antes de que se pasara al altar como imagen principal (en 1982), esta capilla se llenaba de devotos para rezar sus novenas. Asimismo, destaca la gran labor de los sacerdotes Antonio Bandrés (CMF) y Ángel Alegre (CMF) en la configuración $y$ difusión del culto entre la gente de bajos recursos, y en la proyección de San Judas Tadeo como el santo de las causas "difíciles" o "desesperadas" en México.

El presente artículo identifica en este periodo de 1955 a 1970, procesos que pusieron en contacto a la devoción, ya que estuvieron involucradas las primeras oleadas migratorias campo-ciudad durante el periodo de Sustitución de importaciones (1940-1970), que constituyeron un medio de difusión y expansión espacial del culto de San Judas Tadeo entre los creyentes católicos de México, así como, las migraciones hacia Estados Unidos y sus retornos, ya mencionadas. En esta etapa de configuración espacial, social y religiosa de la Ciudad de México, se encuentra que el culto $y$ el templo de San Hipólito fueron apropiados por sectores predominantemente marginados, muchos de ellos, migrantes que habían llegado a la ciudad, particularmente al Centro Histórico, como espacio neurálgico. Todos ellos, en ese momento, probablemente con necesidades, carencias y anhelos comunes, con algunas similitudes de la devoción en Estados Unidos.

Estos cambios, aunados a las grandes transformaciones globales producto de la Guerra Fría, las revoluciones sexuales, el movimiento hippie y, en México, el movimiento

$9 \quad$ Para la institución católica, Reverendo Padre.

10 R. Rivera, comunicación personal, julio de 2018. 
estudiantil del 68, gestaron cambios culturales y, para 1982, la sociedad mexicana había tenido una fuerte transformación acentuada por el cambio de sistema económico al neoliberalismo y la crisis generada, que crearon un sentimiento de incertidumbre $y$ desesperanza entre los mexicanos (Macías, 2014). De tal suerte, en 1982, se registró un segundo surgimiento de la devoción, cuando la imagen de San Judas Tadeo pasó de la capilla de los Santos Mártires Mexicanos al altar principal, apropiando y despojando a la imagen de San Hipólito de su espacio privilegiado; fue una segunda apropiación del templo, como lo propone este artículo, pues, a San Judas Tadeo se le adjudican grandes milagros en las crisis, en las causas difíciles y desesperadas.

Ahora bien, en 1985, cuando la Ciudad de México fue sacudida por los fuertes sismos de septiembre, se tuvo un elemento más de desestabilización social $y$ de acercamiento a la devoción; si bien, el templo fue afectado en su vida parroquial por el daño causado a su arquitectura, la devoción continuó. En 1989, se registró un incendio provocado por el gran número de veladoras que ofrendaban los creyentes $y$, en 1990, la gran cantidad de devotos reunidos en el templo demandó la instalación de un equipo de sonido, para que la homilía fuera escuchada extramuros del templo (Misioneros Claretianos, 1992 y Macías, 2014). Para el nuevo milenio, se configuraba una devoción a San Judas Tadeo renovada y resemantizada respecto a su inicial e incipiente llegada en la década de 1930, y actualmente, se apropia por tercera vez (desde 2002), cada 28 de mes del templo de San Hipólito, a modo de una manifestación devocional, política y festiva. Hoy, es una población devota denominada "sanjudera", configurada, principalmente, por grupos marginados, con presencia indígena, inclusive, sujetos adictos y al margen de la ley, cuya imagen ha sido proyectada mediáticamente $y$ ha creado estigmas sociales y espaciales (Cuadro 2).

CUADRO 2

PROCESOS DE APROPIACIÓN DEL TEMPLO DE SAN HIPÓLITO Y SAN CASIANO POR LA DEVOCIÓN A SAN JUDAS TADEO

\begin{tabular}{ccc}
\hline PROCESO & PERIODO & SITUACIÓN \\
\hline Primer proceso & $1955-1970$ & Anclaje y difusión \\
Segundo proceso & $1982-1990$ & Consolidación \\
Tercer proceso & $2002-2018$ & Resemantización \\
\hline
\end{tabular}

Fuente: Elaboración propia.

LA TERCERA APROPIACIÓN DEL TEMPLO DE SAN HIPÓLITO POR UNA RESEMANTIZADA DEVOCIÓN A SAN JUDAS TADEO (2002-2018)

El grupo de investigación social Habitus, en su artículo, Una mirada a la devoción de los jóvenes a San Judas Tadeo (2011b), reconoce que existen diversos perfiles de devotos en el templo de San Hipólito, la mayoría de sectores marginados o menos favorecidos, pero no todos jóvenes, adictos o delincuentes, de hecho, identifica a grosso modo patrones espacio-temporales: en las primeras horas de la mañana de un 28 de octubre es común ver a obreros, oficinistas, amas de casa y personas de la tercera edad; más tarde y con el transcurso del día, es más notoria la presencia de jóvenes entre 14 y 29 años, en los vagones del metro Hidalgo, Paseo de la Reforma y Alameda Central. Estos jóvenes, con base en el estudio estadístico de Habitus (2011b), de 182 entrevistados, 39\% trabaja o está en busca de una actividad laboral o escolar; y $62 \%$ estudia en algún nivel educativo. 
Macías (2014 y 2016), por su parte, reconoce esta heterogeneidad de devotos. Respecto al grupo de edad, encuentra a: "jóvenes desplazados", vulnerables ante la situación socioeconómica del país y jóvenes adultos (16 a 25 años), divididos en universitarios y padres de familia. El autor halla también patrones en el espacio y tiempo, pues destaca que, a los jóvenes universitarios rara vez se les puede encontrar en las festividades del 28 de mes. Aunada a esta población, entre los devotos se encuentran a los adultos (29 a 60 años), quienes se acercaron a la devoción mediante sus hijos y acuden en familia; $y$, finalmente, los adultos mayores que conocieron al santo mediante la Biblia. En su análisis por actividad laboral o profesional, distingue a comerciantes (informal y micro) y profesionistas; asimismo, halló a otras poblaciones, como asaltantes, narcotraficantes, convictos $y$ exconvictos; inclusive, pertenecientes a otras religiones como la santería ${ }^{11}$.

En el artículo El consumo de solventes inhalables en la festividad de San Judas Tadeo (Ortiz, Domínguez y Palomares, 2015), de forma muy acertada se enfatiza que, se ha creado en el imaginario social una imagen del joven devoto "monoso" o "vicioso"; sin embargo, al templo de San Hipólito acuden niños, adultos, ancianos y familias enteras. Por lo tanto, busca evitar enfoques superficiales en el estudio de la devoción al santo y su vinculación con personas consumidoras de solventes $y$ en situación marginal; en esto, debe considerarse como un punto neurálgico la posición geográfica del templo de San Hipólito en el Centro

11 La división analítica hecha por Macías (2014-2016) no está construida desde un punto de vista marxista de clases sociales, aunque el elemento económico fue parte de las variables que se tomaron en cuenta para la clasificación. De esta manera, se establecieron tres divisiones principales: a) edad, b) actividad laboral y c) actividades delictivas $y$ otros. La división se basó sobre las observaciones empíricas en el trabajo de campo (cualitativo y cuantitativo), que se llevó a cabo los 28 de mes, de 2012 a 2014; se aplicaron 15 entrevistas estructuradas y 50 semiestructuradas.
Histórico de la Ciudad de México, donde existe una población en situación de calle que lo rodea, y cuya práctica de inhalación de solvente está relacionada con su situación y no directamente con el templo o la devoción. Además, muchas de las personas en situación de calle son migrantes, provenientes de diversos estados de la República Mexicana, y algunos llegan a vivir en cuartos de hotel rentados diariamente (120 a 150 pesos mexicanos), o en viviendas de un solo cuarto (1200 pesos mexicanos mensuales) (Ortiz et ál., 2015).

Ahora bien, poco se ha investigado sobre la postura institucional respecto a esta población juvenil asociada al consumo de activo, actividades ilícitas y en situación de calle, presente en el templo de San Hipólito. Como parte del trabajo de campo de la presente investigación, se encontró que esto estuvo relacionado con una estrategia de acercamiento a los jóvenes vulnerables. Esta estrategia se puso en marcha entre los años 2007 y 2010, fue planeada por un grupo de Claretianos del templo, entre ellos, René Pérez Díaz (CFM), cuyo periodo de actividad en el templo de San Hipólito fue de 2005 a 2010.

El sacerdote R.P. René Pérez ${ }^{12}$ (CFM) confirmón $^{13}$ esta estrategia de inclusión. Los Claretianos, al identificar la fuerte presencia de estos jóvenes en el templo, buscaron un acercamiento a través de la Pastoral Juvenil y desarrollaron estrategias como la elaboración de "Cartas a la banda14" y el "Evangelio con sabor a banda" (paraliturgia), este último por el sacerdote Federico Lozz; estos documentos eran leídos en vez de las homilías y tenían un lenguaje que podía ser entendido por los jóvenes. De hecho, junto con Casa Alianza ${ }^{15}$ y la

12 Actual Secretario Provincial del templo de San Antonio María Claret, en la Ciudad de México.

13 R. Pérez, comunicación personal, septiembre 2018.

14 En la Ciudad de México, es una forma coloquial de llamar a los jóvenes de tribus urbanas.

15 Institución de Asistencia Privada dedicada a la rehabilitación de personas en situación de calle. 
alcaldía de Cuauhtémoc, si bien, se buscó un acercamiento a estos jóvenes para que dejaran las drogas, por ejemplo, mediante la "quema de monas" en plaza Zarco, no se tuvo éxito; $y$, el resto de la feligresía del templo se manifestó en contra, además de crear un estigma sobre estos jóvenes. No obstante, con la remodelación de plaza Zarco (por el Fideicomiso del Centro Histórico, en 2016), aledaña al templo, la población en situación de calle que ahí habitaba y se reunía, tuvo que dejar la plaza; por ende, disminuyó su presencia en el templo.

Para los sacerdotes del templo de San Hipólito, al igual que para Ortiz et ál. (2015), en esta imagen del templo vinculada a los vicios e indigencia, debe considerarse la presencia de personas en situación de calle que habitan alrededor del templo, por ejemplo, de plaza Zarco. Cabe recordar que el templo se encuentra en el Centro Histórico, un espacio de síntesis de los grandes males (migración e indigencia) de la Ciudad de México. Por lo anterior, la presencia de jóvenes y niños en situación de calle no está vinculada exclusivamente con la devoción a San Judas Tadeo. Asimismo, desde esta perspectiva, los jóvenes vulnerables, de tribus urbanas o de sujetos al margen de la ley, también se relacionan con el templo, en gran medida, por la cercanía de colonias con fuertes problemas de delincuencia $y$ violencia (Doctores, Obrera, Tepito o la Guerrero); esto, sin olvidar el papel del desarrollo del transporte en la ciudad, como las estaciones de metro cercanas al templo, Bellas Artes, Hidalgo y Guerrero; así como, la línea 4 del metrobús (Terminal 2-Buenavista y San Lázaro-Buenavista), que ha facilitado la llegada de los sectores más vulnerables provenientes de la periferia, pero que su condición social y económica vulnerable no los hace delincuentes ni adictos.

Así, otros perfiles, como amas de casa, obreros y estudiantes de clases populares, entre otros, han tenido presencia desde inicios de la configuración de la devoción en el templo de San Hipólito, y no está asociada únicamente a jóvenes vulnerables o delincuentes. Sumado a esta heterogeneidad de la tercera apropiación del templo, esta investigación ha identificado la presencia indígena y población creyente producto de la migración (occidente, centro y sur de México), característica de las urbes latinoamericanas $y$ de una religiosidad popular urbana, $y$ que ha sido académicamente invisibilizada.

A manera de conclusión, el templo de San Hipólito tiene una "posición geográfica de ruptura" (Mancillas, 2012, p.48), existe una frontera simbólica al encontrase en el límite entre la zona turística y empresarial de Paseo de la Reforma y las colonias y barrios populares, como la colonia Guerrero, en el Centro Histórico de la Ciudad de México.

\section{UN CULTO POPULAR URBANO: JÓVENES VULNERABLES, SANTEROS E INDÍGENAS}

A fin de exponer los resultados preliminares del trabajo etnográfico y de su observación participante, resulta imprescindible hablar, brevemente, de la metodología empleada; así como de los autores consultados para su ejecución: Taylor y Bogdan (1987), Ghasarian (2008), Guber (2004 y 2011) y Ferrándiz (2011).

Con estas referencias, previamente, se llevaron a cabo tres experiencias exploratorias, entre 2015 y 2016, para identificar el metadiscurso de los sanjuderos y de las autoridades del templo (sacerdotes y administrativos). Posteriormente, se logró un involucramiento al interior del templo a través del trabajo voluntario, a fin de llevar a cabo la observación participante y el contacto más directo con los devotos. Este involucramiento tuvo una duración de más de un año, de septiembre de 2016 a noviembre de 2017, con una asistencia metódica cada 28 de mes y de forma azarosa, de tres a cuatro veces durante los días restantes del mes.

Durante estos días, fueron aplicadas entrevistas semiestructuradas $y$ a profundidad, excepto por el 28 de octubre, fiesta anual de San Judas Tadeo, dado el contexto festivo y su poca pertinencia para la aplicación de entrevistas; en consecuencia, se aplicaron encuestas que dan profundidad analítica y que constan de cuatro bloques: datos 
personales, antecedentes históricos del templo, significado del templo para el devoto y comportamiento del devoto. No obstante, apelando a la reflexividad en la etnografía, de 2017 a 2018, se ha continuado con tareas muy específicas para complementar la investigación ${ }^{16}$.

De acuerdo con las 63 encuestas aplicadas en diferentes horas del día, entre dos fiestas anuales a San Judas Tadeo en el templo de San Hipólito (28 de octubre), las edades de los peregrinos encuestados van desde los 17 hasta los 72 años de edad; con 36 casos concentrados en edades entre los 17 a los 32 años (57\%); seguido por 23 casos en el rango de 33 a los 56 años (37\%); con una caída a partir de los 57 años hasta los 72 , con solo cuatro casos registrados (6\%). En cuanto a género, el reporte fue equilibrado, con 33 mujeres (52\%) y 30 hombres (48\%). Respecto al nivel de escolaridad, se presentaron 12 casos con educación primaria (19\%) y 24 con educación secundaria (38\%), correspondiente a la educación básica; con preparatoria se presentaron 18 casos (29\%); tres con un profesional técnico (5\%); solo cuatro con licenciatura (6\%) y con ningún grado, se registraron dos casos (3\%) (Gráfico 1).

\section{GRÁFICO 1 \\ ESCOLARIDAD Y OCUPACIÓN DE LOS DEVOTOS A SAN JUDAS TADEO 2016-2017}

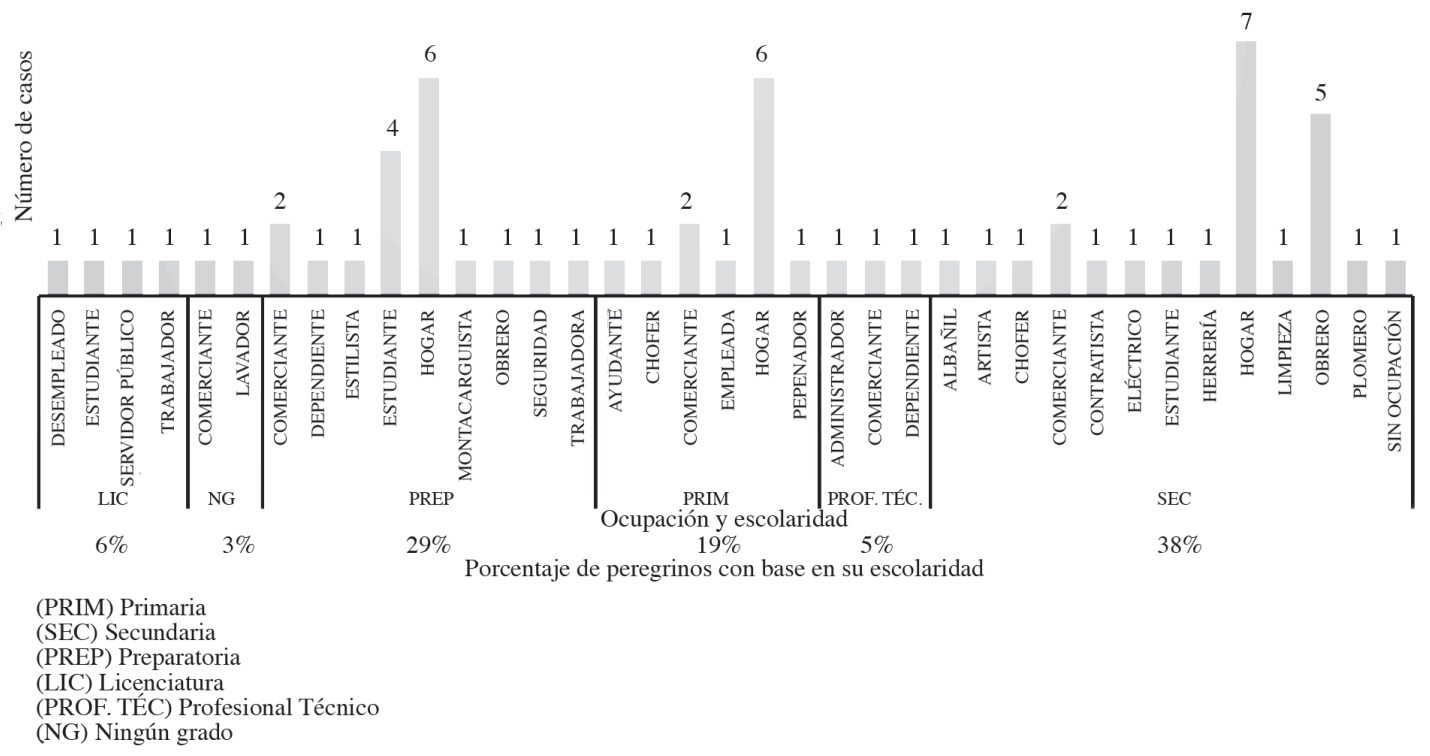

Fuente: Elaboración propia con base en trabajo de campo, 2016-2018.

16 Entrevistas a sacerdotes del templo de San Hipólito y de San Antonio María Claret; acceso al libro de testimonios del templo, donde los devotos escriben peticiones o agradecimientos; $y$ finalmente, el reconocimiento de altares en las calles de la Ciudad de México y Estado de México, como forma de territorialización de la devoción. 
Entre las ocupaciones de los peregrinos encuestados, estas fueron variadas, pero en su mayoría de baja remuneración (94\%), a excepción de algunos; así, entre los casos más recurrentes están: 19 casos que señalaron dedicarse al hogar, 6 son obreros, 8 comerciantes y 6 estudiantes. Entre el resto de los casos se pudieron hallar 7 peregrinos empleados en opciones informales: pepenador, plomero, eléctrico, albañil, herrero, lavador de autos y limpieza. Entre otras ocupaciones identificadas están: 1 estilista, 2 choferes, 1 montacarguista, 1 dependiente de farmacia, 1 dependiente de tienda de abarrotes, hasta 1 artista (pintor), que no especificaron su situación laboral (formal o informal). Sin dar más detalle de su labor, se hallaron 2 trabajadores, 1 empleado y 1 ayudante; solo se registró 1 desempleado y 1 sin ocupación (sin buscar o haber tenido trabajo). Además, se pudieron encontrar empleados de manera formal y con mejores expectativas económicas (6\%), entre ellos, 1 servidor público, 1 oficial de seguridad (judicial), 1 administrador $y$ 1 contratista (Gráfico 1).

Cruzada la información cuantitativa con información cualitativa obtenida en el trabajo etnográfico, efectivamente, el nivel de escolaridad es básico (primaria 19\% y secundaria $38 \%)$ entre la mayoría de devotos a San Judas Tadeo, por ende, los trabajos u ocupaciones en los que pueden emplearse y autoemplearse son mal remunerados $y / 0$ informales. De tal suerte, no cuentan con prestaciones, especialmente seguro social (salud), como es el caso de comerciantes informales, albañiles o empleadas de limpieza. Como ya fue explicitado, los estudiantes de licenciatura o profesionistas se presentaron en casos muy aislados (6\%), su presencia no es notable los 28 de mes ni de las 20:00 horas del día; por su parte, los oficinistas que trabajan en el corredor financiero de Paseo de la Reforma y otras oficinas cercanas al Centro Histórico, tienen presencia a las primeras horas de la mañana y posterior a las seis de la tarde de un 28 de mes, cuando han salido de sus labores. Ciertamente, su presencia tampoco es notable, no así para los judiciales, los "judas", presentes en las primeras horas del día. Evidentemente, este análisis devela que no son los jóvenes sin "oficio ni beneficio" la población mayoritaria, pues muchos tienen un empleo, y en otros casos estudian.

Las condiciones socioeconómicas de los peregrinos en el templo de San Hipólito no son fortuitas, existe un patrón de procedencia espacial que sustenta sus características: alcaldías y municipios con alto y muy alto índice de marginación ${ }^{17}$ y delincuencia en la Ciudad de México y su periferia, resultado del fenómeno migratorio campo-ciudad (1940-1970), y de la expulsión de la población hacía afuera de la ciudad central, en 1980. Esa población obligada a migrar ante el abandono del campo, llegaron a la Ciudad de México y sus alrededores en búsqueda de suelo más barato para vivir, sin los servicios básicos como seguridad, salud, acceso a la educación, ni oportunidades laborales.

En el caso de la ciudad, los peregrinos proceden de alcaldías como Azcapotzalco, Venustiano Carranza, Gustavo A. Madero,

17 Con base en cuatro dimensiones: acceso a la educación, salud, vivienda y bienes. Medida por AGEB (Área Geoestadística Básica) urbanas de las zonas metropolitanas de México. Entre las alcaldías y municipios con mayor número de población en AGEB urbanas con alto y muy alto grado de marginación (2010), se encuentran: la alcaldía de Gustavo A. Madero, Iztapalapa, Milpa Alta, Tlalpan y Xochimilco, en la Ciudad de México; y los municipios de Zaragoza, Chalco, Chimalhuacán, Ecatepec, Ixtapaluca, Naucalpan, Nezahualcóyotl, Nicolás Romero, La Paz, Texcoco, Tlalnepantla, Toluca y Valle de Chalco Solidaridad, en el Estado de México (ConAPo, 2010). Mier y Terán, Vázquez y Ziccardi (2012), elaboraron un índice de pobreza urbana, integrado por un conjunto de variables agrupadas en cinco componentes: población, salud, educación, empleo y vivienda, mediante los que se definieron indicadores, tanto a nivel de AGEB's como a nivel local (colonias). Así, con datos del Censo del 2000, de los 8605239 habitantes de la Ciudad de México (antes Distrito Federal), 2.8 millones de personas vivían en condiciones de muy alta y alta pobreza, equivalente al 32,7\% del total de la población, distribuidos en: Milpa Alta, Tláhuac, Xochimilco, con baja densidad de población e inclusive, condiciones de ruralidad; así como, Álvaro Obregón, Iztapalapa, Gustavo A. Madero, estas dos últimas las más pobladas y con condiciones muy precarias de vivienda $y$ deterioro de equipamiento urbano y servicios. 
Álvaro Obregón, Iztacalco, Iztapalapa, Tláhuac y Cuauhtémoc, entre otras. En Cuauhtémoc, en el Centro y donde se localiza el templo, se registraron peregrinos de colonias populares $y$ con incidencia delictiva, como Guerrero, Tepito, Buenos Aires, Obrera y Doctores ${ }^{18}$. Respecto a su periferia, los peregrinos proceden de Ecatepec, Chalco, Valle de Chalco, Coacalco, Chimalhuacán, Ixtapaluca, Nezahualcóyotl,
Huixquilucan, Tlalnepantla, Tultitlán, Naucalpan y Toluca ${ }^{19}$, en el Estado de México. En Nezahualcóyotl, Chimalhuacán y Ecatepec se tienen estratos sociales muy bajos y con alta incidencia delictiva. Además, Iztapalapa, Venustiano Carranza, Cuauhtémoc, Iztacalco, Xochimilco y Tláhuac; Nezahualcóyotl y Chimalhuacán, concentran población indígena (originaria y migrante) (Mapa 1).

MAPA 1

PROCEDENCIA DE LOS SANJUDEROS DENTRO DE LA ZONA METROPOLITANA DE LA CIUDAD DE MÉXICO (ZMCM) 2018

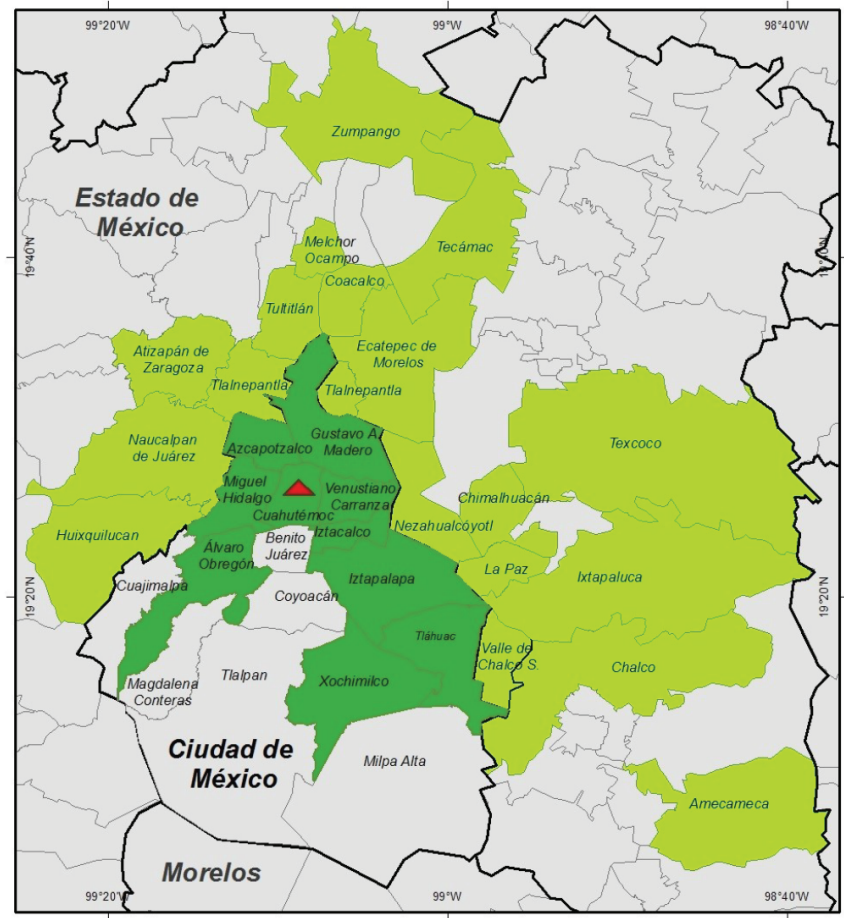

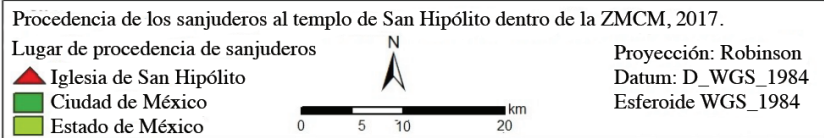

Fuente: $\quad$ Elaboración propia con base en el trabajo de campo, 2016-2018.

18 De acuerdo con la Procuraduría General de Justicia (2018), la Ciudad de México reportó que de enero a marzo de 2018, Cuauhtémoc, Miguel Hidalgo y Azcapotzalco fueron las alcaldías con mayor tasa de delitos de alto impacto, seguido por Venustiano Carranza, Xochimilco e Iztapalapa.
19 Perteneciente a la Zona Metropolitana del Valle de Toluca. 
De manera concluyente, la triangulación de información de las encuestas y los registros de campo arrojaron que las procedencias de los devotos de México se concentran, principalmente, en la zona norte $y$ oriente de la ciudad $y$ la periferia en el Estado de México (ZMCM) ${ }^{20}$, durante los 28 de mes; pero el 28 de octubre, sus alcances espaciales se extienden a Hidalgo, Puebla, Veracruz, Querétaro, Guanajuato, Morelos y hasta Oaxaca. Ahora bien, el resto de los días sus alcances espaciales no suelen rebasar la ciudad y algunos municipios más cercanos del Estado de México. Se observan a su vez, aunque con menor visibilidad, devotos de alcaldías con niveles muy bajos de marginación ${ }^{21} y$ buenos ingresos económicos, como Benito Juárez y, de otros estados de la República Mexicana, concentrados principalmente en fechas marcadas por el calendario ritual $y$ de contexto vacacional, es decir, raramente un 28 de mes $y$, específicamente de octubre. En cuanto a los devotos provenientes de alcaldías con buenos niveles socioeconómicos, con los que se tuvo contacto durante la observación participante, en algunos casos, llegan los días previos o posteriores al 28 de mes, entre 26 y 27 o 30, ya que la presencia de las "masas", con base en sus argumentos identificados en pláticas casuales y entrevistas, les parece "peligrosa".

Como hallazgo etnográfico, los 28 de mes se encontró una comunidad, cada vez más visible, de indígenas migrantes de primera, segunda y tercera generación, provenientes del centro (Puebla y Estado de México) y sur del país (Guerrero, Veracruz y Oaxaca); en el caso de las primeras generaciones, se asientan en el municipio de Ecatepec, donde habitan cuartos. La mayoría se emplean en la venta de plantas $y$ flores de manera ambulante, así como de artesanías, pues dicen "ganar más que en las

20 La ZMCM está conforma por 16 alcaldías de la Ciudad de México, 59 municipios del Estado de México y uno de Hidalgo (Tizayuca).

21 Con base en el índice de pobreza urbana (población, salud, educación, empleo y vivienda) de Mier y Terán (et ál. 2012), las alcaldías de Benito Juárez, parte de Cuauhtémoc, Coyoacán, Miguel Hidalgo e Iztacalco, se encuentran en condiciones de baja y muy baja pobreza. jornadas en el campo". En fechas distintas al patrón temporal del 28 de mes, se identificaron también dos devotos migrantes del Estado de Jalisco y Chiapas, de primera y segunda generación, correspondientemente.

Como era de esperarse, en la devoción a San Judas Tadeo en el templo de San Hipólito, son notables los elementos simbólicos de la cosmovisión indígena mesoamericana y coloniales, particularmente en dos circunstancias: en paralelismo e inclusive, sincretismo, entre sus santos, y la personalización de sus imágenes. Entre las variadas imágenes de San Judas Tadeo que llegan a verse entre la multitud, pueden encontrarse aquellas ataviadas con sombrero de palma y morral al costado, en alusión a la agricultura; por ejemplo, se halló un peregrino ${ }^{22}$ que dijo ser migrante de primera generación y personalizar así a su "San Juditas" , porque él, es de Tierra Caliente, en Guerrero, donde se dedicaba al campo; $y$ respecto al inicio de cuaresma, se halló una imagen de San Judas Tadeo con una vestimenta de chinelo ${ }^{23}$, y en cuyo centro destacaba la imagen de la Virgen de Guadalupe. A esto habría que sumar, el paralelismo entre Simón, hermano de Judas Tadeo, con el San Simón o Maximón guatemalteco, ante la idea de una hija de migrantes chiapanecos, que encuentra en sus nombres su equivalencia simbólica. Por su parte, un hombre Huichol ${ }^{24}$, que llega desde Jalisco a la Ciudad de México a vender sus artesanías en el mercado de la Ciudadela, dijo traer siempre que puede una luz a "San Juditas", como lo lleva al Sol, en territorio wixárica (Figuras 1 y 2).

$22 \quad$ Comunicación personal, diciembre de 2016.

23 Es un personaje mestizo que se originó en Tlayacapan, Morelos, México. Son danzantes, cuya vestimenta (máscaras de madera, sombreros con plumas y túnicas de terciopelo con llamativos bordados alusivos a dioses o personajes prehispánicos) surgió como alusión sarcástica de los indígenas a los señores españoles y a los sacerdotes durante la Colonia. Constituyen personajes principales en los carnavales o fiestas religiosas, aunque para la iglesia católica es una manifestación paganareligiosa; se llevan a cabo al inicio de cuaresma. En la Ciudad de México forman parte de las fiestas patronales de los pueblos originarios.

Comunicación personal, julio de 2017. 
FIGURA 1

SAN JUDAS "CHINELO”

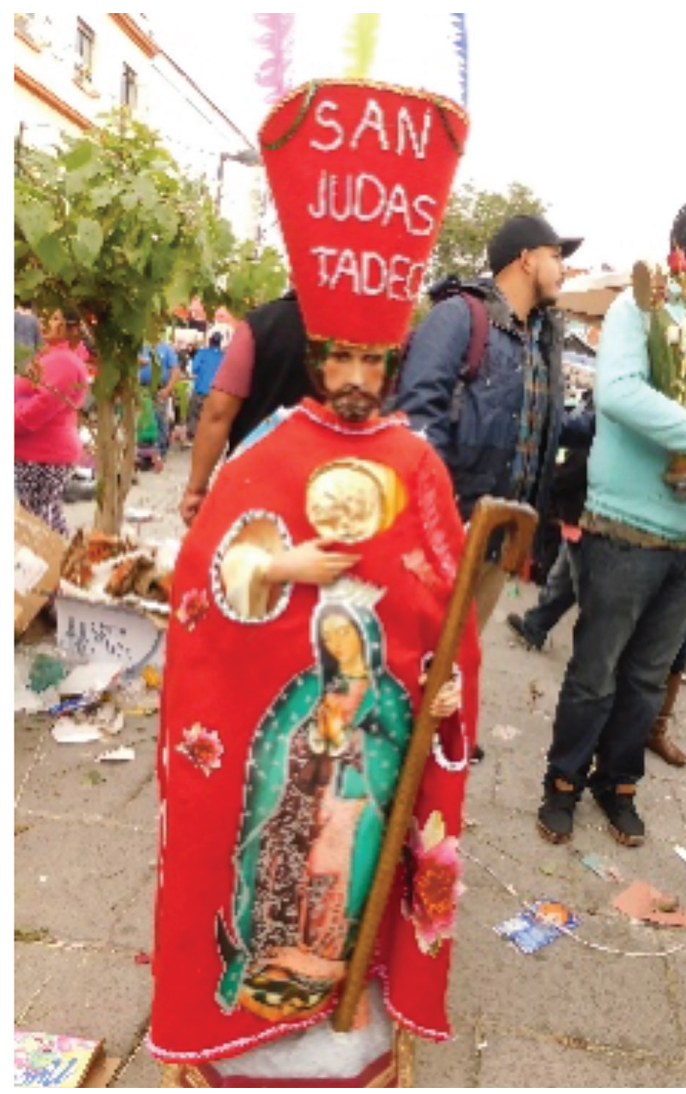

Fuente: Fotografía tomada por Thania S. Álvarez Juárez $(28 / 10 / 2016)$

Al traer sus elementos simbólicos del contexto rural al ámbito urbano, las ofrendas de los indígenas devotos a San Judas Tadeo en el templo de San Hipólito son distintas al resto de los peregrinos. Por ejemplo, un grupo de jóvenes indígenas, entre los 20 a los 25 años, provenientes de Veracruz y hablantes del náhuatl, suelen los 28 de mes, regalar espigas de trigo, para que "no falte el pan en la mesa"; contrariamente, el resto de los peregrinos ofrecen dulces, comida, escapularios, rosarios, entre muchos otros objetos.

Las personas indígenas entrevistadas, dicen acudir a San Judas Tadeo por trabajo y salud, como la mayoría de los peregrinos, así como para rogar que no se les discrimine, y porque en el templo de San Hipólito "se sienten
FIGURA 2

SAN JUDAS Y SAN SIMÓN

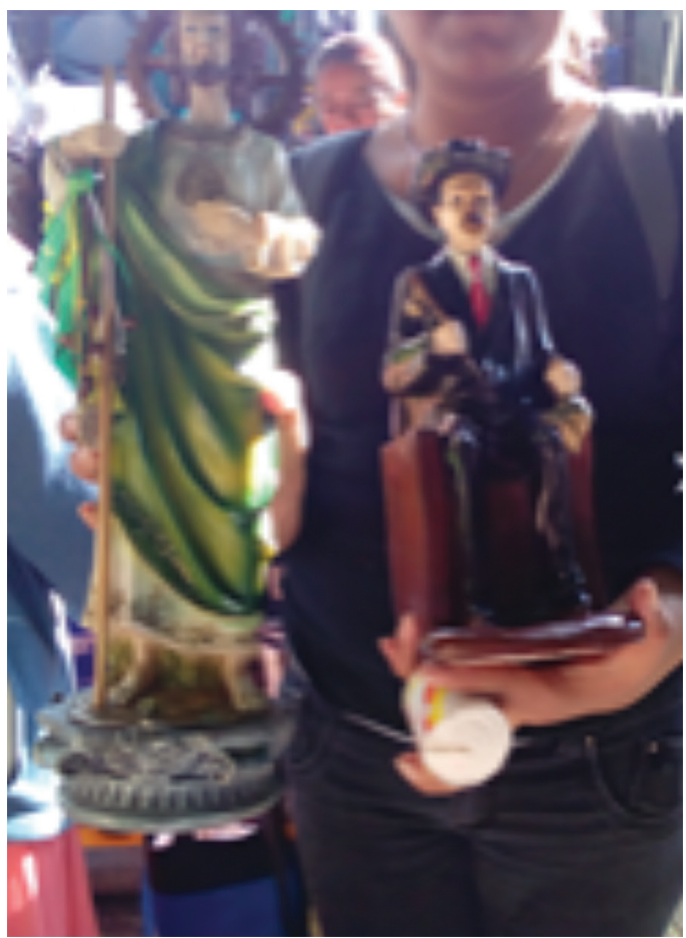

Fuente: Fotografía tomada por Thania S. Álvarez Juárez (29/10/2016).

bien". Para ellos es sumamente humillante la burla por su vestimenta e idioma, pues acostumbran gritarles "indios".

Respecto a otros peregrinos, no faltó la presencia de elementos afroamericanos como la santería. Si se presta atención, en las imágenes de bulto de San Judas Tadeo cuelgan múltiples collares con los colores del santo (amarillo, verde, blanco y dorado), a modo de elekes santeros (cuentas de cristal), que son regalados entre los peregrinos y que tienen un gran valor simbólico para ellos; sin embargo, también es posible encontrar la venta de elekes, como tal, en los puestos ambulantes del espacio circundante al templo, pero con los colores de los orishas (santos yorubas) y la imagen de San Judas Tadeo al centro. Un claro ejemplo de este 
sincretismo, es un peregrino cuya imagen de San Judas Tadeo fue pintada por él, con los siete colores de las Siete potencias africanas.

\section{CONCLUSIONES}

Si bien la presencia indígena no es una generalidad entre los devotos que asisten al templo de San Hipólito, es visible y deja abierta la posibilidad de un estudio detallado para conocer su continuidad y su relación con el fenómeno migratorio de escala regional. Asimismo, el abordaje del culto a San Judas Tadeo debe dar atención a su nueva relación con elementos de religiones afroamericanas y su resemantización con elementos simbólicos locales. Ambos casos requieren tratamientos independientes y representan nuevas sendas de investigación para los científicos sociales, coadyuvan al rompimiento de estigmas en torno a la devoción en el templo; dan cuenta de la existencia de otros tipos de devotos $y$ otras posibilidades de estudiar el culto, no solo desde el discurso de "jóvenes adictos" o "delincuentes". Como se explicitó, la vinculación entre estos jóvenes y el templo se relaciona, en mayor medida, con la ubicación del templo (colonia Guerrero, Centro Histórico) $y$ con estrategias de acercamiento por parte de un grupo de claretianos, como lo fue el "Evangelio con sabor a banda" y "Cartas a la banda".

Estos hallazgos también exponen, a grandes rasgos, las carencias económicas y sociales de la Ciudad de México, pues los sanjuderos son representativos de los sectores menos favorecidos que revelan mediante su discurso, el contexto de desigualdad social y discriminación. Por ello, el estudio de la religiosidad popular no debe subestimarse; puede entenderse como una forma de apropiación del espacio por los desposeídos y de su capacidad para tener sus creaciones identitarias, de su proyecto social mediante una devoción. En el caso de los devotos a San Judas Tadeo, es la forma de poseer aquello que se les ha arrebatado o negado: poder, identidad y espacio, del derecho al territorio. San Hipólito y sus espacios circundantes son territorio "sanjudero" versus la segregación espacial del Centro Histórico.

Así pues, los estudios religiosos vistos por algunos como ociosos, pueden ser verdaderos reflejos de la situación social, de los cuales pueden partir políticas públicas. El estudio de la devoción a San Judas en el templo de San Hipólito deja ver la urgencia por la atención de las personas en situación de calle que le rodea. Más allá de expulsarlos mediante la rehabilitación de "espacios públicos" como plaza Zarco, se necesitan programas de atención social que resuelvan de raíz la habitual relación migraciónindigencia (mestiza o indígena) en la Ciudad de México. De la misma manera, imperan programas que promuevan el respeto $y$ dignificación a las diversas culturas indígenas que integran históricamente al país, que lo identifican y lo enriquecen.

La discriminación en México es sumamente común, de tal manera, no solo los indígenas se sienten agredidos, otros devotos a San Judas Tadeo manifestaron ser motivo de burla y discriminación al ser señalados como "sanjuderos" o "chacas", en el transporte público y calles de la ciudad, cuando salen los 28 de mes hacia el templo de San Hipólito; inclusive, entre familiares $y$ amigos son vistos como posibles "delincuentes y adictos". De hecho, entre algunos citadinos, el 28 de mes en el templo de San Hipólito es conocido como el "chaca fest" o "chaca day", ignorando las grandes necesidades de la Ciudad de México, a modo de una criminalización de la pobreza.

En todo caso, todos ahí se reúnen para agradecer a San Juditas por lo recibido e implorar mensualmente salud, trabajo, dinero, salir de la cárcel, educación y protección familiar, finalmente todas causas desesperadas; esto, sin olvidar la visibilización social y el encuentro con otros. Es la manifestación, a través de una religiosidad popular urbana, de la incertidumbre social, de las carencias no solo económicas, también emocionales; en parte, sin ninguna intención de reducir a un enfoque funcionalista a la devoción, los creyentes delegan en San Judas Tadeo las funciones y obligaciones del Estado; $y$ en una lógica de resemantización, le piden el "paro" (favor) para salir de la cárcel o agradecen por haber librado una balacera. No solo San Juditas, a su vez, Guadalupe, la Santa Muerte, Malverde, Maximón, y las Siete potencias africanas suelen echarles la mano en este "mundo terrenal". 


\section{REFERENCIAS}

Carballo, C. (2009). Repensar el territorio de la expresión religiosa. Carballo, C. (coord.), Cultura, territorios y prácticas religiosas. Buenos Aires: Prometeo Libros.

CONAPO. (2010). Índice de marginación urbana. México. Recuperado de http://www. sideso.cdmx.gob.mx/documentos/2017/ diagnostico/conapo/2010/Indice $\% 20$ de\%20marginacion\%20urbana.pdf

De la Torre, R. (2013). La Religiosidad Popular. Encrucijada de las nuevas formas de la religiosidad contemporánea y la tradición (el caso de México). Ponto Urbe (12), 1-24. Recuperado de https://journals.openedition.org/pontourbe/581

González, J. (1996). El catolicismo popular mexicano y su proyecto social. Blancarte, R. (comp.) El pensamiento social de los católicos mexicanos. México: FCE.

Gutiérrez, D. (septiembre-diciembre de 2005). Multirreligiosidad en la Ciudad de México. Economía, Sociedad y Territorio, V (19), 617-658. Recuperado de http://www. redalyc.org/pdf/111/11101907.pdf

Habitus, G. d. (mayo-junio de 2011a). San Judas Tadeo en la Ciudad de México. Los orígenes de la devoción. Revista Presencia Apostólica, (47), 6-7.

Habitus, G. d. (marzo- abril de 2011b). Una mirada a la devoción de los jóvenes a San Judas Tadeo. Revista Presencia Apostólica, (46), 6-7.

Luna, M. (2016). Significaciones y resignificaciones sobre la celebración de San Judas Tadeo en los creyentes que acuden al templo de San Hipólito. (Tesis de Licenciatura en Comunicación). FESAcatlán, México.

Macías, R. (2014). San Juditas no me falla. Historia y devoción a San Judas Tadeo (1922-2014). (Tesis de Maestría en Historia y Etnohistoria). ENAH, México.

Macías, R. (2016). Entre espacio y tiempo. Devoción a San Judas Tadeo en el templo de San Hipólito de la Ciudad de México. Mitológicas, XXXI, 52-82. Recuperado de http://www.redalyc.org/ pdf/146/14649178004.pdf
Mancillas, Y. (2012). Religiosidad al margen. Escenarios, violencias y empatías en los cultos a San Judas Tadeo en la Ciudad de México y Espiritismo Marialioncero en Caracas. (Tesis de Maestría). Universidad Nacional Autónoma de México: México.

Masferrer, E. (2013). Religión, poder y cultura. En sayos sobre politica y diversidad de creencias. México: Libros de la Araucaria.

Marzal, M. (2002). Tierra Encantada. Tratado de Antropología Religiosa de América Latina. España: Trotta / Pontificia Universidad Católica del Perú.

Mejía, P. (2012) Los reggaetoneros y San Judas Tadeo. Espacialidad e identidad juvenil a partir de la devoción, el cuerpo y la música. (Tesis de Licenciatura en Geografía Humana). UAM-I, México.

Mier y Terán, A., Vázquez, I. y Ziccardi, A. (2012). Pobreza urbana, segregación residencial y mejoramiento del espacio público de la Ciudad de México. Ziccardi, A. (Coord.), Ciudades del 2010: entre la sociedad del conocimiento y la desigualdad social. México: PUEc.

Misioneros Claretianos. (1992). Iglesia de San Hipólito y San Casiano. Primer centenario de la Comunidad Claretiana en San Hipólito, 1982-1992. México: IMC Publicaciones, S.A. de C.V.

Misioneros Claretianos. (1994). Más de cien años en San Hipólito, desde 1832. México: Hilmac, S.A. de C.V.

Misioneros Claretianos. (2014). San Judas Tadeo. Semblanza de un apóstol y su devoción en el templo de San Hipólito de la Ciudad de México. México: Carmona Impresores, S.A. de c.v.

Oehmichen, C. (2015). La tradicional presencia indígena en el Centro Histórico de la Ciudad de México. Seminario Permanente (PUEC). Centro histórico de la Ciudad de México V3, 117-121.

Ortiz, A., Domínguez, M. y Palomares, G. (noviembre-diciembre de 2015). El consumo de solventes inhalables en la festividad de San Judas Tadeo. Salud Mental, 38, 427-432. Recuperado de http://www. 
scielo.org.mx/pdf/sm/v38n6/0185-3325sm-38-06-00427.pdf

Osri, R. A. (1996). Thank You, St. Jude. Women's Devotion to the Patron Saint of Hopeless Causes. Usa: Yale University Press.

Parker, C. (1993). Otra Lógica en América Latina. Religión popular y Modernización Capitalista. Chile: Fondo de Cultura Económica.

PGJ. (marzo de 2018). Boletín estadístico de la incidencia delictiva en la Ciudad de México. Recuperado de https://www.pgj. cdmx.gob.mx

Rosendahl, Z. (1996). Espaço e religião: uma abordagem geográfica. Río de Janeiro, Brasil: UERJ, NEPEC.
Rosendahl, Z. (1999). Hierópolis: o sagrado e o urbano. Rio de Janeiro: EDUERJ.

Santiago, I. (2013) La devoción a san Judas Tadeo, espacio teológico para expresar la fe de un pueblo y lugar de encuentro con el resucitado. (Tesina para obtener en grado de Bachiller en Teología). Instituto de Formación Teológica Intercongregacional de México, Afiliado a la Facultad De Teología De La Pontificia Universidad Javeriana, México.

Fecha de ingreso: 18/10/2018 Fecha de aprobación: 19/02/2019 
